0408, 1001) positive and SE negative. To overcome potential bias, multivariate logistic regression analysis was done in this retrospective cohort.

Results: They were divided into 47 SE positive patients (65.3\%) and 25 SE negative patients $(34.7 \%)$. The retention rate of abatacept treatment at week 52 were $95.3 \% / 47.1 \%$ (SE positive/SE negative, $p<0.0001$, log-rank test), respectively. Adjusted hazard ratio for abatacept discontinuation due to lack of efficacy was 8.94 (95\% Cl: 2.95-34.1, $\mathrm{p}<0.0001$, Multivariable Cox proportional hazards regression model) in SE negative group compared to SE positive group. The EULAR good response rate at week 24 were $74.5 \% / 20.0 \%$ (SE positive/SE negative, $p<0.0001$, Fisher's exact test), respectively. Simplified Disease Activity Index (SDAI) remission rate at week 24 were $55.3 \% / 20.0 \%$ (SE positive/SE negative, $\mathrm{p}=0.004$, Fisher's exact test), respectively. Multivariate logistic regression revealed the odds ratio of EULAR good response and SDAI remission achievement in SE positive patients was 23.2 and $6.73(95 \% \mathrm{Cl}$ : $5.10-152.0, p<0.0001$ and $1.70-32.3, p=0.006)$, respectively.

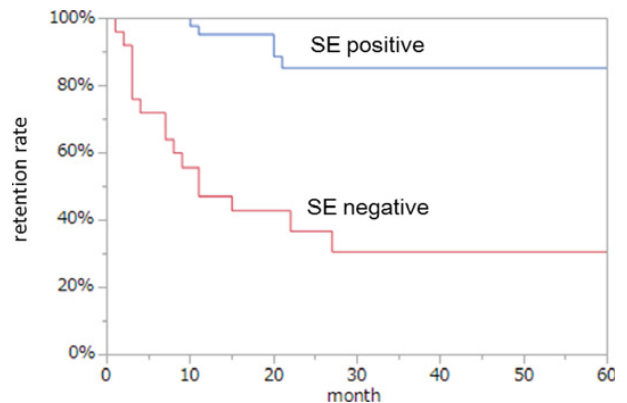

Conclusions: Abatacept is strictly effective to SE positive RA patients.

Disclosure of Interest: K. Oryoji Grant/research support from: Ono, Speakers bureau: Abbvie, Chugai, Astellas, Mitsubishi-Tanabe, Pfizer, Janssen, Eisai, UCB and Ono, K. Yoshida: None declared, S.-I. Mizuki Speakers bureau: Abbvie, Astellas, Mitsubishi-Tanabe, Pfizer, Janssen, Eisai, UCB and Ono

DOI: 10.1136/annrheumdis-2017-eular.5586

\section{FRI0219 ASSOCIATION BETWEEN CONVERSION TO ACPA/RF SERONEGATIVE STATUS AND CLINICAL OUTCOMES FOLLOWING TREATMENT WITH ABATACEPT IN COMBINATION WITH METHOTREXATE COMPARED WITH METHOTREXATE ALONE IN PATIENTS WITH EARLY RHEUMATOID ARTHRITIS AND POOR PROGNOSTIC INDICATORS}

D. Jansen ${ }^{1}$, P. Emery ${ }^{2}$, J. Smolen ${ }^{3}$, R. Westhovens ${ }^{4}$, M. Le Bars ${ }^{5}$,

S. Connolly ${ }^{6}$, J. Ye ${ }^{6}$, R. Toes ${ }^{1}$, T. Huizinga ${ }^{1} .{ }^{1}$ Leiden University Medical Center, Leiden, Netherlands; ${ }^{2}$ University of Leeds and Leeds Musculoskeletal Biomedical Research Unit, Leeds, United Kingdom; ${ }^{3}$ Medical University of Vienna, Vienna, Austria; ${ }^{4}$ UZ Gasthuisberg, Leuven, Belgium; ${ }^{5}$ Bristol-Myers Squibb, Rueil-Malmaison, France; ${ }^{6}$ Bristol-Myers Squibb, Princeton, United States

Background: RA is characterized by the production of autoantibodies, including anti-citrullinated protein antibodies (ACPA) and RF, which are associated with poor prognosis in RA..$^{1-3}$ More data on the clinical significance of ACPA/RF seroconversion in response to treatment are needed. Evidence suggests a role for T cells in ACPA production. 2,3

Objectives: This post hoc analysis investigated the effect of the T-cell costimulation modulator abatacept (ABA) in combination with MTX vs MTX alone on conversion of ACPA positive (+) and RF+ patients (pts) to seronegative status, and the relationship between conversion to seronegative status and clinical response. Methods: Data from a double-blind, randomized, Phase III study (AGREE; NCT00122382) conducted in MTX-naïve pts with early RA ( $\leq 2$ years) and poor prognostic factors (ACPA+ and/or RF+ with evidence of erosions) were included. ${ }^{4}$ Pts were randomized to ABA ( $\sim 10 \mathrm{mg} / \mathrm{kg}$ IV according to weight)+MTX or placebo+MTX (MTX alone) in a 12-month (M) double-blind phase followed by 12M of open-label ABA+MTX. Autoantibody titres were assessed at baseline and $6 \mathrm{M}$ and $12 \mathrm{M}$ of the double-blind phase by ELISA. Pts with titres below the threshold for positivity (ACPA $5 \mathrm{AU} / \mathrm{mL} ; \mathrm{RF}$ [lgM] $15 \mathrm{IU} / \mathrm{mL}$ ) at M6 or M12 were considered to have converted to seronegative status. The relationship between conversion to ACPA seronegative status and clinical response at M6 and M12 was determined. All analyses were descriptive and based on pts with available DAS28 (CRP) and CDAl data at baseline and $\mathrm{M} 6$ and $\mathrm{M} 12$.

Results: A total of 435 and $461 \mathrm{pts}$, respectively, were ACPA+ or RF+ at baseline and had known serostatus at M6 and M12. At 6M, 6.6\% (15/227) and $17.0 \%$ (39/230) of ABA+MTX pts were ACPA and RF negative, respectively, vs $2.9 \%$ (6/208) and 9.5\% (22/231) of MTX pts. At 12M, 7.1\% (15/212) and 18.5\% (41/222) of ABA + MTX pts were ACPA and RF negative, respectively, vs $4.5 \%(9 / 198)$ and $14.6 \%(32 / 219)$ of MTX pts. A higher proportion of pts receiving ABA + MTX who converted to ACPA seronegative status achieved remission (DAS28 $[C R P]<2.6$ or $C D A I \leq 2.8)$ compared with ABA + MTX-treated pts who remained ACPA+ or with pts treated with MTX alone regardless of whether they converted to seronegative status or not (Figure). Pts receiving ABA + MTX who converted to ACPA seronegative status also had a numerically higher cumulative probability of achieving sustained remission (DAS28 [CRP] <2.6) and lower radiographic progression than pts receiving MTX who converted to seronegative status or pts in either treatment group who remained ACPA+ (data not shown).

Figure, Proportion of Patients Achieving Remission, According to DAS28 (CRP)-Defined or CDAI Criteria, by ACPA Seronegative/Seropositive Status
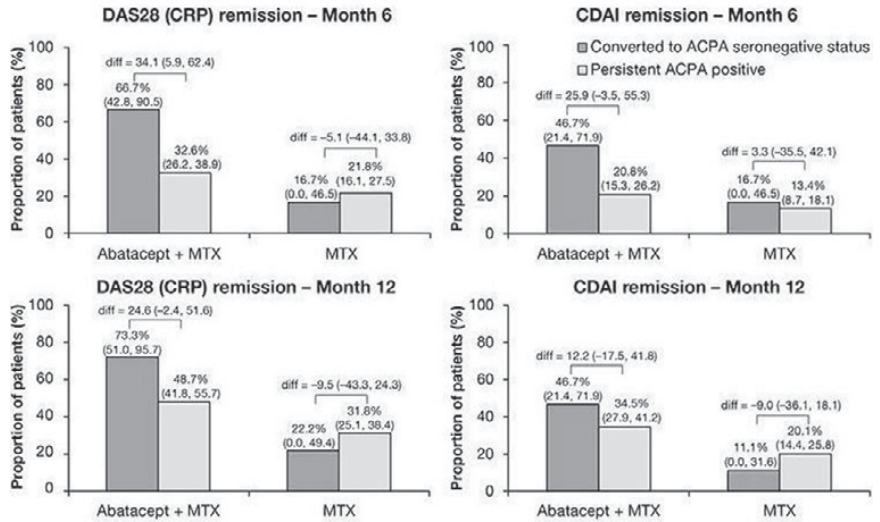

Baseline to Month 6 and baseline to Month 12 were carried out as separate analyses.

Conclusions: Compared with MTX alone, treatment with abatacept + MTX was more likely to result in conversion to ACPA/RF seronegative status in pts with early erosive RA. Conversion to ACPA seronegative status was associated with better clinical and radiographic outcomes.

References:

[1] Scott DL, et al. Lancet 2010;376:1094-108.

[2] Hecht C, et al. Ann Rheum Dis 2015;74:2151-6.

[3] Aletaha D, et al. Arthritis Res Ther 2015;17:229.

[4] Rombouts Y, et al. Ann Rheum Dis 2016;75:578-85.

Disclosure of Interest: D. Jansen: None declared, P. Emery Grant/research support from: AbbVie, Merck, Pfizer, Roche, Consultant for: AbbVie, BristolMyers Squibb, Merck, Pfizer, Roche, Lilly, Novartis, Samsung Bioepis, J. Smolen Grant/research support from: AbbVie, Janssen, Lilly, MSD, Pfizer, Roche, Consultant for: AbbVie, Amgen, AstraZeneca, Astro, Bristol-Myers Squibb, Celgene, Celltrion, Chugai, Gilead, GSK, ILTOO, Janssen, Lilly, Medlmmune, MSD, NovartisSandoz, Pfizer, Roche, Samsung, Sanofi, UCB, R. Westhovens Grant/research support from: Roche, Consultant for: Janssen, Celltrion, Galapagos, Speakers bureau: Bristol-Myers Squibb, M. Le Bars Shareholder of: Bristol-Myers Squibb, Employee of: Bristol-Myers Squibb, S. Connolly Shareholder of: Bristol-Myers Squibb, Employee of: Bristol-Myers Squibb, J. Ye Shareholder of: Bristol-Myers Squibb, Employee of: Bristol-Myers Squibb, R. Toes: None declared, T. Huizinga Grant/research support from: EU \& Dutch Arthritis Foundation, Consultant for: Abbott Laboratories, Biotest AG, Bristol-Myers Squibb, Crescendo Bioscience, Inc, Novartis Pharmaceuticals Corporation, Pfizer Inc, Roche, sanofi-aventis, Schering-Plough, UCB, Inc., Eli Lilly, Speakers bureau: Abbott Laboratories, Biotest AG, Bristol-Myers Squibb, Novartis Pharmaceuticals Corporation, Pfizer Inc, Roche, sanofi-aventis, Schering-Plough DOI: 10.1136/annrheumdis-2017-eular.1716

\section{FRI0220 ALLOGENEIC MESENCHYMAL PRECURSOR CELLS (MPCS): A NOVEL APPROACH TO TREATING BIOLOGIC REFRACTORY RHEUMATOID ARTHRITIS}

S. Kafaja ${ }^{1}$, K.R. Segal ${ }^{2}$, D. Skerrett ${ }^{3}$, S. Itescu ${ }^{4}$, D.E. Furst ${ }^{5} .{ }^{1}$ Division of Rheumatology, David Geffen School of Rheumatology, University of California Los Angeles, Los Angeles; ${ }^{2}$ Mesoblast, Inc; ${ }^{3}$ Mesoblast, Inc, New York, United States; ${ }^{4}$ Mesoblast, Inc, Melbourne, Australia; ${ }^{5}$ Arthritis Associates of Southern California, Los Angeles, United States

Background: Allogeneic STRO-3 immunoselected mesenchymal precursor cells (MPCs) derived from bone marrow of healthy donors are a potent, homogeneous cell population which can be activated by pro-inflammatory cytokines to release factors which polarize pro-inflammatory monocytes and $\mathrm{T}$ cells to an antiinflammatory state. This is the first in human trial to assess MPC therapy in biologic refractory RA, a disease driven by monocyte and $T$ cell activation.

Objectives: To assess the safety and tolerability and to explore the clinical efficacy of MPC therapy in RA.

Methods: MSB-RA001 is a phase $1 \mathrm{~B} / 2 \mathrm{~A}$ randomized, double-blind, placebocontrolled, sequential, dose-escalation trial to assess the safety and explore efficacy of a single intravenous (IV) infusion of MPCs in patients with active RA who had failed to respond to at least one biologic. Efficacy endpoints included ACR $20,50,70$, ACR core components, $\mathrm{HAQ}$ and DAS28. Patients were randomized to receive one IV infusion of MPC 1 million cells/kg $(n=16), 2$ million cells/kg $(n=16)$, or placebo $(n=16)$ in 2 sequential dose cohorts. The primary study period was 12 weeks.

Results: Patients in all 3 treatment groups ( $\mathrm{N}=16$ per group) were comparable in mean age (55 y), gender ( $73 \%$ women), duration of RA (14 years) and 
prior biologic exposures. Importantly, MPC infusions were well-tolerated with no adverse infusion reactions or serious adverse events (SAE) noted over 12 weeks. At 4 and 8 weeks, both MPC groups achieved higher ACR20 levels than placebo, with the placebo group reaching similar levels by 12 weeks. Notably, at 12 weeks both ACR50 rates $(31,27,19 \%)$ and ACR70 rates $(27,20,0 \%)$ were higher for the $2 \mathrm{M} / \mathrm{kg}$ and $1 \mathrm{M} / \mathrm{kg}$ MPC groups than placebo (Figure 1); $\mathrm{p}=0.04$ for ACR70 in $2 \mathrm{M} / \mathrm{kg}$ vs. placebo. The MPC groups showed dose-related greater improvement in pain, patient global assessment (PGA) of disease and physical function vs. placebo with greater efficacy in the $2 \mathrm{M} / \mathrm{kg}$ group (Table 1). At 12 weeks PGA and Pain were significantly reduced in $2 \mathrm{M} / \mathrm{kg} \mathrm{MPC}$ group vs. placebo (both $\mathrm{p}=0.04$ ). MPC treatment was associated with significantly improved health-related physical function by the HAQ. Minimal clinically important difference in $\mathrm{HAQ}$ defined as reduction of at least -0.22 points was achieved in $93 \%$ of $2 \mathrm{M} / \mathrm{kg} \mathrm{MPC}$ vs. $25 \%$ of placebo at 12 weeks $(p=0.003)$

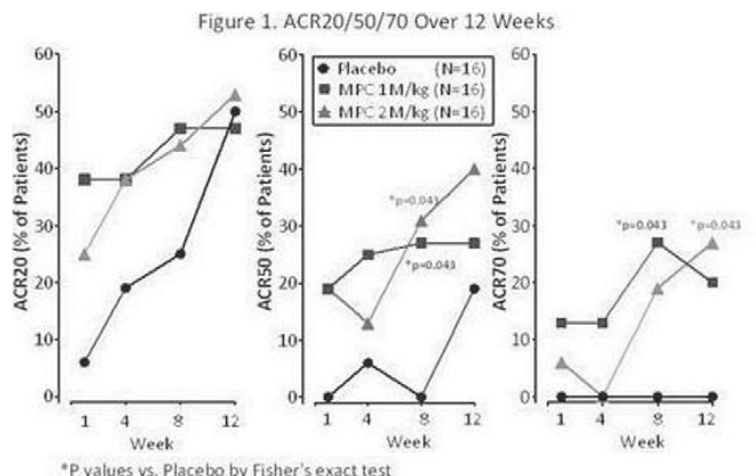

Table 1 Summary of Week 12 Efficacy Assessments

\begin{tabular}{lccc}
\hline & Placebo & MPC 1M/kg & MPC 2M/kg \\
\hline & $\mathrm{N}=16$ & $\mathrm{~N}=16$ & $\mathrm{~N}=16$ \\
ACR20 (\%) & $50 \%$ & $47 \%$ & $50 \%$ \\
ACR50 (\%) & $19 \%$ & $27 \%$ & $31 \%$ \\
ACR70 (\%) & $0 \%$ & $20 \%$ & $27 \%^{*}$ \\
DAS-28 CRP (\%) & & & \\
$\quad$ Response: $\leq 3.2$ & $19 \%$ & $27 \%$ & $36 \%$ \\
$\quad$ Remission: $<2.6$ & $13 \%$ & $20 \%$ & $21 \%$ \\
HAQ Change from baseline $\leq-0.22(\%)$ & $37.5 \%$ & $53 \%$ & $93 \%^{* *}$ \\
ACR Core Components [Change (SE) from baseline] & & \\
$\quad$ Tender joints & $-9.8(1.9)$ & $-5.8(1.9)$ & $-11.2(1.9)$ \\
$\quad$ Swollen joints & $-7.7(1.6)$ & $-6.1(1.6)$ & $-10.1(1.6)$ \\
Investigator global assessment & $-21.6(6.5)$ & $-32.6(6.5)$ & $-35.6(6.6)$ \\
$\quad$ Patient global assessment & $-6.7(6.5)$ & $-17.5(6.5)$ & $-25.7(6.5)^{*}$ \\
$\quad$ Patient pain & $-8.4(6.6)$ & $-16.2(6.6)$ & $-28.6(6.7)^{*}$ \\
\hline P<0.0S: $*$ P<0.005 & & &
\end{tabular}

Conclusions: A single infusion of MPCs was well-tolerated in RA patients. While the efficacy results are encouraging, further assessment including dose optimization is needed. The current trial is a unique early phase trial that shows promise of a future role for MPCs as a therapeutic option in biologic-refractory RA patients, a subset of the RA population with substantial remaining medical need. Disclosure of Interest: S. Kafaja: None declared, K. Segal Employee of: Mesoblast, Inc., D. Skerrett Employee of: Mesoblast, Inc., S. Itescu Employee of: Mesoblast, Inc., D. Furst: None declared

DOI: 10.1136/annrheumdis-2017-eular.1106

\section{FRI0221 DOES SEROPOSITIVITY INFLUENCE DIFFERENTIALLY DRUG DISCONTINUATION OF BIOLOGIC ANTIRHEUMATIC AGENTS WITH NON-ANTI-TNF MODE OF ACTION?}

A. Finckh ${ }^{1}$, D. Courvoisier ${ }^{1}$, J.-E. Gottenberg ${ }^{2}$, X. Mariette $^{3}$, J. Morel ${ }^{4}$, S.A. Bergstra ${ }^{5}$, V. Hernandez ${ }^{6}$, C. Codreanu ${ }^{7}$, T.K. Kvien ${ }^{8}$, M.J. Santos ${ }^{9}$, K. Pavelka ${ }^{10}$, M. Hetland ${ }^{11}$, K. Chatzidionysiou ${ }^{12}$, J. Askling ${ }^{12}$, C. Turesson ${ }^{13}$, C. Gabay ${ }^{1}, \mathrm{R}$. Van Vollenhoven ${ }^{14}$. ${ }^{1} \mathrm{HUG}$, Geneva, Switzerland; ${ }^{2} \mathrm{CHU}$, Strassbourg; ${ }^{3}$ Paris-S University, le Kremlin-Bicêtre; ${ }^{4} \mathrm{CHU}$, Montpellier, France; ${ }^{5}$ University Medical Center, Leiden, Netherlands; ${ }^{6}$ Hospital Clinic, Barcelona, Spain; ${ }^{7}$ Univ of Medicine and Pharmacy, Bucharest, Romania; ${ }^{8}$ Diakonhjemmet Hospital, Oslo, Norway; ${ }^{9}$ Rheuma.PT, Lisbon, Portugal; ${ }^{10}$ Institute of Rheumatology, Prague, Czech Republic; ${ }^{11}$ Glostrup Hospital, Glostrup, Denmark; ${ }^{2}$ Karolinska Institute, Stockholm; ${ }^{13}$ Lund University, Lund, Sweden; ${ }^{14}$ AMC, Amsterdam, Netherlands

Background: Rheumatoid factor (RF) and anti-citrulinated protein antibodies (ACPA) are used as diagnostic tools, but may also be used as prognostic factors or as predictors of response to therapy, as these biomarkers have been associated with better clinical responses to some bDMARDs.

Objectives: To examine whether seropositivity has a similar impact on drug discontinuation of different bDMARDs with a non-anti-TNF mode of action (non-aTNF bDMARDs).

Methods: This is a pooled analysis of 10 observational European RA registries
(FR, CZ, DK, NO, PT, RO, ES, SE, CH, NL). Inclusion criteria were a diagnosis of $R A$, initiation of treatment with abatacept (ABA), rituximab (RTX) or tocilizumab (TCZ) and available information on RF and/or ACPA status. The exposure of interest was seropositivity, which was defined as positive if RF or ACPA was positive and negative if both were negative. The primary endpoint was overall drug discontinuation, defined as the period between treatment initiation and treatment discontinuation. Because national differences may constitute a potential confounder, we only included national registries with information for all 3 bDMARD and pooled data across registries only after excluding significant effect modification by country. Drug discontinuation was analyzed using a Cox proportional hazard model, including drug, seropositivity, and their interaction, adjusting for age, gender, disease duration, baseline DAS28, concomitant synthetic DMARD (sDMARDs), number of previous sDMARDs and bDMARDs, and stratifying by country and calendar year.

Results: We found no effect modification by country, allowing us to pool data from 12040 patients (Table). In crude analyses, seropositivity was associated with a lower drug discontinuation with all 3 bDMARD ( $p$-value interaction 0.22 ), with a hazard ratio for seropositive vs. seronegative (HR) 0.89 (95\% Cl: 0.82-0.97). In adjusted analyses, seropositivity remained associated with a lower drug discontinuation, but the effect differed by drug ( $p$ interaction 0.01): ABA: HR for seropositive vs. seronegative: $0.76(95 \% \mathrm{Cl} 0.66-0.88)$, RTX: $0.88,(95 \%$ Cl: $0.70-1.10)$, and TCZ: $1.08,(95 \% \mathrm{Cl}: 0.89-1.31)$. Two-by-two drug to drug comparisons showed that the effect of seropositivity differed between $A B A$ and TCZ $(p=0.004)$, but not between ABA and RTX $(p=0.29)$, or between TCZ and RTX $(p=0.16)$. Other factors associated with discontinuation were higher baseline disease activity and more previous bDMARD.

\begin{tabular}{|c|c|c|c|}
\hline & $\begin{array}{c}\text { ABA } \\
N=3089\end{array}$ & $\begin{array}{c}\text { RTX } \\
N=5539\end{array}$ & $\begin{array}{c}\mathrm{TCZ} \\
\mathrm{N}=3412\end{array}$ \\
\hline $\begin{array}{l}\text { Seropositivity, } N(\%) \\
\text { RF+ } \\
\text { R } A \text { ACPA+ }\end{array}$ & $\begin{array}{l}2602(84.2 \%) \\
2234(73.0 \%) \\
1861(68.5 \%)\end{array}$ & $\begin{array}{l}5176(93.4 \%) \\
4655(84.1 \%) \\
3703(85.0 \%)\end{array}$ & $\begin{array}{l}2920(85.6 \%) \\
2682(79.3 \%) \\
1826(73.7 \%)\end{array}$ \\
\hline Female sex, $\mathrm{N}(\%)$ & $2463(79.7 \%)$ & $4543(82.0 \%)$ & $2692(78.9 \%)$ \\
\hline & $56.8(1$ & $58.9(12.1)$ & $55.9(12.8)$ \\
\hline Disease d & $11.8(9.3)$ & $12.5(9.3)$ & $11.2(9.6)$ \\
\hline DAS28 at bas & $4.9(1.5)$ & $5.2(1.5)$ & $4.7(1.4)$ \\
\hline N previous SDMARD, $\mathrm{N}(\%)$ & & & \\
\hline $\begin{array}{l}\leq 1 \\
\geq 2\end{array}$ & $\begin{array}{l}917(32.3 \%) \\
1925(67.7 \%)\end{array}$ & $\begin{array}{l}1988(40.1 \%) \\
2972(59.9 \%)\end{array}$ & $\begin{array}{l}1245(39.2 \%) \\
1928(60.8 \%)\end{array}$ \\
\hline $\mathrm{N}$ previous bDMARD, $\mathrm{N}(\%)$ & & & \\
\hline $\begin{array}{l}\leq 1 \\
\geq 2\end{array}$ & $1903(62.1 \%)$ & $3818(69.2 \%)$ & $1733(52.5 \%)$ \\
\hline & & & \\
\hline $\begin{array}{l}\text { Concomitant sDMARD, N }(\%) \\
\text { Median follow-up time [yrs] }\end{array}$ & $1657(53.6 \%)$ & $3899(70.5 \%)$ & $2251(66.1 \%)$ \\
\hline $\begin{array}{l}\text { Calendar year of treatment } \\
\text { initiation, } 10^{\mathrm{th}}-90^{\mathrm{th}} \text { percentile }\end{array}$ & $2008-2014$ & $2006-2012$ & $2009-2015$ \\
\hline
\end{tabular}

Conclusions: Data from this pooled european registry analysis suggests that seropositivity is associated with lower drug discontinuation of non-aTNF bDMARDs. This effect differed between drugs and was significant for ABA, but not for TCZ or RTX. The impact of seropositivity on other measures of effectiveness still needs to be investigated.

Disclosure of Interest: A. Finckh Grant/research support from: BMS, Speakers bureau: Abbvie, Roche, Pfizer, UCB, D. Courvoisier: None declared, J.-E. Gottenberg: None declared, X. Mariette: None declared, J. Morel: None declared, S. A. Bergstra: None declared, V. Hernandez: None declared, C. Codreanu Grant/research support from: Abbvie, Pfizer, Roche, Consultant for: MSD, Pfizer, Roche, Paid instructor for: Abbvie, Bristol-Myers Squibb, Janssen, MSD, Pfizer, Roche and UCB, T. K. Kvien: None declared, M. J. Santos: None declared, K. Pavelka: None declared, M. Hetland Grant/research support from: AbbVie, BMS, MSD, Biogen, UCB, Pfizer, Eli Lilly, Roche, Speakers bureau: Orion, K. Chatzidionysiou Consultant for: AbbVie, Pfizer, Eli Lilly, UCB, Roche, J. Askling Grant/research support from: Abbvie, UCB, Lilly, Janssen, Samsung, Pfizer, MSD, Roche, C. Turesson Grant/research support from: Abbvie, Pfizer, Roche, Consultant for: MSD, Pfizer, Roche, Paid instructor for: Abbvie, Bristol-Myers Squibb, Janssen, MSD, Pfizer, Roche and UCB, C. Gabay: None declared, R. Van Vollenhoven: None declared

DOI: 10.1136/annrheumdis-2017-eular.6006

\section{FRI0222 SUSTAINED RESPONSE FOLLOWING DISCONTINUATION OF METHOTREXATE IN PATIENTS WITH RHEUMATOID ARTHRITIS TREATED WITH SUBCUTANEOUS TOCILIZUMAB: RESULTS FROM A RANDOMIZED CONTROLLED TRIAL (COMP-ACT)}

J. Kremer $^{1}$, W. Rigby ${ }^{2}$, N. Singer ${ }^{3}$, C. Birchwood ${ }^{4}$, D. Gill ${ }^{4}$, W. Reiss ${ }^{4}$, J. Pei $^{4}$, M. Michalska ${ }^{4} .{ }^{1}$ Albany Medical College and The Center for Rheumatology, Albany, NY; ${ }^{2}$ Geisel School of Medicine, Dartmouth College, Lebanon, NH; ${ }^{3}$ School of Medicine, MetroHealth System, Case Western Reserve University, Cleveland, $\mathrm{OH} ;{ }^{4}$ Genentech, Inc., South San Francisco, CA, United States

Background: Methotrexate (MTX) is frequently administered in combination with biologics for the treatment of rheumatoid arthritis (RA). MTX may be subsequently discontinued due to intolerance or nonadherence, and/or to reduce medication burden once disease control is achieved. Previous studies have established the efficacy of tocilizumab (TCZ) initiated as monotherapy (MONO), but the impact 